\title{
Editorial
}

Teaching foreign languages to young learners has gained substantial attention across the world in recent years. More and more countries have lowered the age of foreign language learning to the beginning of primary school or even lower. In most educational contexts, a communicative or meaningfocused teaching approach has typically been implemented, although a clear understanding of young learners' communicative competence in their foreign language has still not been properly and comprehensively defined (Johnstone, 2000; Butler \& Zeng, 2014). What is more, our knowledge about how communicative abilities among young foreign language learners can be assessed most effectively lacks a theoretical and empirical background. It is therefore of utmost importance to identify the main factors and their co- and inter/intrarelations in order to finally better understand the way young learners learn foreign languages and how they should be assessed so as to demonstrate their language knowledge and competences.

As argued above, there many reasons why this issue is dedicated to assessing foreign language proficiency of young learners. Assessment has been neglected in many subject matter disciplines, and language assessment is no exception. In addition, empirically based information on assessment methodology for young learners is too scarce to offer sufficient information for teachers, language counsellors and language policy decision makers. It is, therefore, more than welcome that the first three articles address the issues of assessing young foreign language learners from different perspectives.

In addition to the articles addressing the main topic of this issue (young foreign language assessment) there are two more texts bringing interesting discussions on (1) the use of comics to reduce gender differences in reading literacy at the primary level of education, and (2) the challenges of the academic profession in Croatia, whose practitioners find themselves between teaching and doing research. The issue concludes with a book review of an internationally compiled publication on teaching English to young learners.

The first article, written by Dina Tsagari and entitled Assessment Orientations of State Primary EFL Teachers in Two Mediterranean Countries, investigates the centrality of classroom-based assessment (CBLA) in English as a foreign language (EFL) teaching among primary EFL teachers in Cyprus and Greece. The study answers three relatively important questions: (1) What are the CBLA practices that Greek and Cypriot EFL primary school teachers employ with their young learners? (2) What level of training in CBLA areas do the EFL teachers have? and (3) To what extent do teachers perceive a need for further in-service 
training in CBLA? The data show that both groups of teachers use tests as their basic CBLA method with varying frequency, but that their tests include a limited range of language skills and knowledge (vocabulary and grammar). The test tasks are rather unchallenging and the criteria teachers use to select testing materials and/or provide feedback (a deficit-oriented rather than positively oriented approach) on test results are not consistent. Whereas teachers express their doubts regarding the use of tests, the results show that alternative forms of assessment have only been implemented sporadically in primary schools in both countries. In addition, teachers do not seem to have a thorough understanding of alternative assessment methods due to a lack of appropriate training. What needs to be researched further is the teachers' perception of their personal professional development needs in CBLA. For example, the teachers are aware of alternative and formative ways of assessment (e.g., portfolio, peer- or self-assessment) but they are not able to implement them efficiently. In spite of the fact that the teachers express a need for training in CBLA, they still have difficulties specifying their needs in a concrete way. However, there are some promising signs that the participating EFL teachers are seriously considering the use of CBLA and are open to training initiatives to broaden their assessment literacy. This leads to the important finding that existing BA and MA language assessment courses and workshops also need to capitalise on teachers' existing experience and practices, to recognise the reality and constraints influencing teachers' assessment practices, and to encourage an action-research orientation to professional development, which will result in the combining of theory with practice in the classroom. This study also clearly shows that the implementation of the CEFR for assessment purposes and, in particular, assessment for learning, which is one of the most important issues in early language learning today, is very slow in classrooms in Europe. It seems that language learning still relies on summative testing of vocabulary, grammar and writing in the so-called communicative language classroom.

The second article addresses some open issues of diagnostic assessment, which several language researchers have identified as an important but neglected area that has not been as well developed as other types of language assessment, such as proficiency and achievement testing. It was not until 2004 that Alderson (2004) designed a list of features that many people agree characterise most diagnostic approaches and could be transferred to the foreign language assessment discipline. It is only recently that researchers have started to develop a framework that encompasses the entire enterprise of diagnostic assessment, and that identifies learners' strengths and weaknesses in the less well-documented areas of second/foreign language reading and listening (Harding, Alderson, \& Brunfaut, 2015). The current article, Diagnostic Tests in Czech for Pupils with a First Language Different from the 
Language of Schooling, authored by Kateřina Vodičková and Yvona Kostelecká, attempts to validate a new diagnostic test developed for primary school pupils whose L1 is other than Czech. Since the number of immigrants in the Czech population is likely to grow even more, its relevance will only increase in the future. The development of a diagnostic test for L2 primary school learners represents one of the first attempts to design an assessment instrument that would help teachers and immigrant learners to integrate more efficiently into Czech society. The authors identify fields in which further development is desirable, such as financial and human support, the training of administrators, examiners/raters and experts in providing feedback to the test users, etc. An important finding refers to the need to provide prompt and detailed feedback to test takers, teachers and schools. Another revealing discovery relates to the need to discover the impact of the diagnostic test on teaching and learning processes of Czech as a second language.

Learners between Childhood and Adulthood: Assessing Writing Competences of Teens Learning French as a Foreign Language, written by Meta Lah, is the third article tackling language assessment as a topic of discussion. The article introduces young adolescents learning French as a foreign language, who commonly find themselves between childhood and adulthood and may be identified as a "between-age group". The question set by the author as to which descriptors to use in order to analyse the writing skills of these learners is therefore highly relevant. Several parameters were included in the analysis (task achievement, communicative suitability, orthography, grammar and vocabulary), albeit based on a small sample of writing scripts collected from pupils participating in a national French language competition at the end of upper primary school. The results show that the pupils were able to meet the form requirements better than the length requirements, and that the content of the letters was mostly suitable. The pupils were also expected to use basic vocabulary and simple grammatical structures mostly correctly and appropriately. However, the compositions varied greatly regarding the language level. Another important finding refers to the appropriateness of writing assessment descriptors and their relevance as placement CEFR tools. It was discovered that the AYLITT (assessment of young learner literacy linked to the CEFR project) descriptors, which are usually used for young learners, seemed to be more appropriate than the more general CEFR descriptors, which were developed exclusively for adults. The former proved more relevant due to the fact that they are more explicit and include in-between levels (for example, $\mathrm{A}_{1} / \mathrm{A}_{2}$ or $\mathrm{A}_{2} / \mathrm{B}_{1}$ levels), which characterise the language development of young learners and, according to this study, young adolescents, as well.

The next text written by Matjaž Duh and entitled Art Appreciation for Developing Communication Skills among Preschool Children focuses on the 
contemporary teaching of fine arts. The article discusses how works of art may affect children's communication skills. The results of the study show that children respond to works of art in different ways and at a number of levels. It was discovered that children internalised the given artworks and were able to express their emotions in words. The main finding is thus that a systematic development of art appreciation among preschool children may lead to positive effects on their communication competence.

The final article, entitled Between Teaching and Research: Challenges of the Academic Profession in Croatia by Marko Turk and Jasminka Ledić, discusses the synergy between teaching and research at academic institutions in Croatia. The study attempts to identify how academics see their roles: as teachers or/ and as researchers. The authors use a qualitative approach (a standardised semistructured interview) with 60 participating interviewees. The findings reveal that participating academics see their roles most often as teachers, then as teachers and researchers, and finally as researchers. This study brings new perspectives (sometimes contradicting facts) to the research already conducted in Croatia on the challenges facing academic staff in this country. It seems that there is a difference between academics' interests and their perception of themselves as primarily teachers or researchers due to external factors, such as increased teaching load, academic promotion requirements giving priority to research over teaching, nonexistent or negligible support for teaching and doing research, etc.

Readers may also be interested in reading the book review by Barbara Lesničar focusing on the book International Perspectives on Teaching English to Young Learners, edited by Sarah Rich and published by Palgrave Macmillian in 2014. The reviewer highlights the need for more research in the field of teaching English as a foreign language to young learners. English language teaching has spread to young learners' classrooms across the globe, while providing evidence-based and appropriate support to teachers has mostly been negligible or non-existent. Let me conclude with the words of the reviewer: "The fresh insights this volume offers will help teachers to cope with different challenges in their day-to-day practice. .... it is evident that global dialogue about TEYL is not only necessary, but is also beneficial to our field."

\section{KARMEN PIŽORN}

Butler, Y. G., \& Zeng, W. (2014). Young Foreign Language Learners' Interactions During Task-Based Paired Assessments. Language Assessment Quarterly, 11(1), 45-75.

Harding, L., Alderson, J. C., \& Brunfaut, T. (2015). Diagnostic assessment of reading and listening in a second or foreign language: Elaborating on diagnostic principles. Language Testing, 32(3), 317-336. Johnstone, R. (2000). Context-sensitive assessment of modern language in primary (elementary) and early secondary education: Scotland and the European experience. Language Testing, 17, 123-143. 